\title{
A laparoscopic technique for full thickness intestinal biopsy and feeding jejunostomy
}

\author{
W K Eltringham, A M Roe, S W Galloway, R A Mountford, H J Espiner
}

\begin{abstract}
A laparoscopic technique is described, suitable for both full thickness intestinal biopsy and placement of a feeding jejunostomy tube. Its application in three cases is reported. The method is simple, permits full laparoscopic examination of the abdominal contents and being minimally invasive, facilitates early patient recovery.

(Gut 1993; 34: 122-124)
\end{abstract}

Full thickness intestinal biopsy plays an essential role in the diagnosis of certain rare diseases of the small and large intestine including the visceral myopathies, ${ }^{12}$ diffuse lymphoma with or without coelic disease, visceral systemic sclerosis, and non-Hirschprungs motility disorders. ${ }^{3}$ Traditionally the biopsy has necessitated laparotomy or mini-laparotomy but a minimally invasive technique would provide obvious advantages.

Feeding jejunostomy, a concept developed by Delaney, ${ }^{4}$ has been used to provide nutrition for postoperative patients $s^{5}$ and occasionally for the support of patients with chronic intestinal disease. ${ }^{6}$ The tubes may be placed at laparotomy ${ }^{78}$ but in the past decade percutaneous endoscopic techniques to avoid open operation have been developed first for gastrostomy ${ }^{10}$ and

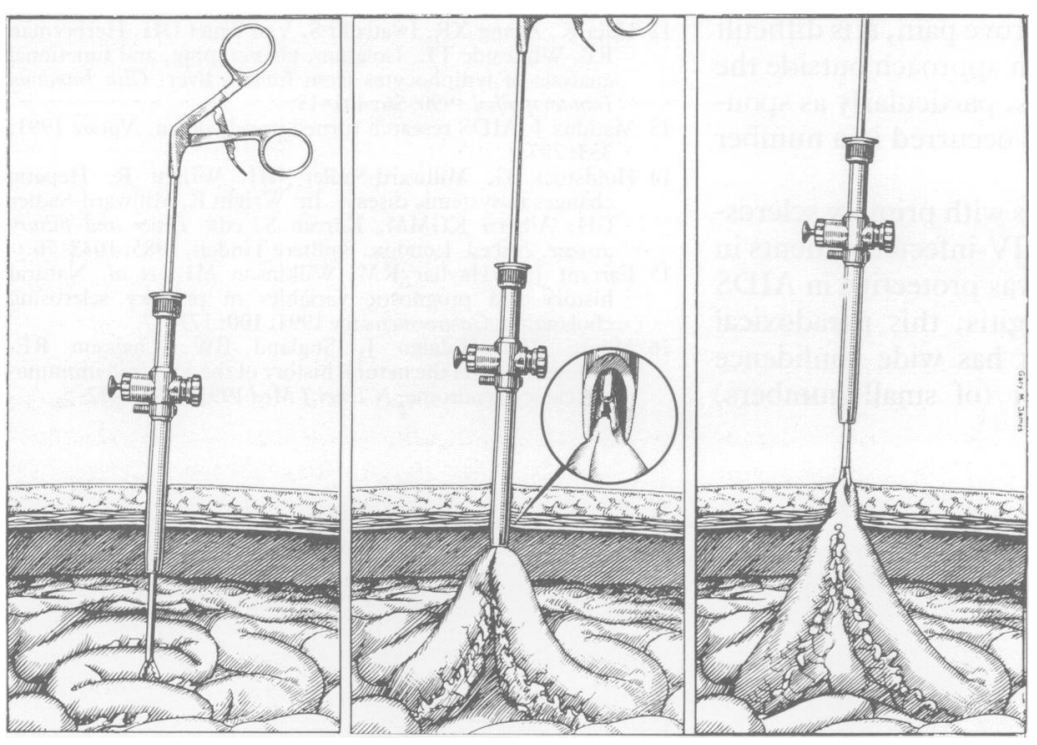

Figure: Sequence showing the technique for laparoscopically delivering the small bowel to the wound surface in preparation for full thickness biopsy or feeding jejunostomy. later for jejunostomy. ${ }^{11-13}$ The procedures for jejunostomy are complex, however, and a number of problems and complications have been recorded. ${ }^{1+15}$

We describe a laparoscopic technique suitable for both full thickness intestinal biopsy and for the placement of a feeding jejunostomy tube and report three cases where the method was applied.

\section{Method}

A pneumoperitoneum is raised in the standard fashion and a $10 \mathrm{~mm} 0^{\circ}$ telescope is introduced through an umbilical port. Operating ports are established in the mid clavicular line $3-5 \mathrm{~cm}$, below the left costal margin $(10 \mathrm{~mm})$ and in the midline half way between the xiphisternum and the umbilicus ( $5 \mathrm{~mm}$ ). A full laparoscopic examination of the abdominal contents is carried out.

\section{INTESTINAL BIOPSY}

The site for biopsy is selected and the bowel grasped by atraumatic forceps introduced through the $10 \mathrm{~mm}$ port. By gentle traction the bowel is pulled into the orifice of the cannula and delivered into the wound by removal of the cannula together with the grasping forceps holding the bowel (Figure). A full thickness biopsy of appropriate size is taken and the bowel returned to the abdominal cavity after suture closure of the defect.

TUBE JEJUNOSTOMY

The duodenojejunal junction is visualised by cephalad displacement of the great omentum and transverse colon. A point is selected approximately $30 \mathrm{~cm}$ beyond the flexure so that the jejunum can be brought to the abdominal wall without tension and with enough laxity to allow the transverse colon to revert to a relatively normal position once the jejunostomy is fashioned. The bowel is delivered into the port wound as above and a suitable jejunostomy tube is inserted and advanced an adequate distance along the distal bowel. After closure of the bowel around the tube four sutures are placed quadradantically in the seromuscular layer adjacent to the point of the tube insertion and the bowel is replaced into the abdominal cavity. With the aid of small wound retractors the peritoneum and deeper muscle layers are exposed and the four sutures are passed through these layers to secure the bowel firmly against the abdominal parietes. 
The various manoeuvres necessary for biopsy and for tube jejunostomy can be undertaken without enlargement of the $1 \mathrm{~cm}$ port incision but in the event of the bowel being thickened, or technical difficulty, there would be no contraindication to a modest enlargement of the wound to facilitate the surgery. We have, however, not found this to be necessary in our small experience. Finally the skin wounds are closed with a single absorbable suture or steristrip dressing.

\section{Case reports}

\section{PATIENT I}

An 18 year old man had suffered growth retardation since the age of 12 years and latterly progressive inanition as a result of anorexia and vomiting. He was initially diagnosed as having coeliac disease but deterioration continued despite a gluten free diet. A laparoscopic full thickness biopsy coupled with the insertion of a 9 Fr gauge fine bore feeding tube (Fresenuls Health Care Group, Basingstoke, England) was performed. Histological examination revealed a familial visceral myopathy. Tube feeding brought about clinical improvement with weight gain of $2 \mathrm{~kg}$ in the first two months. He remains on enteral feeding at six months and has required one change of feeding tube, for displacement, which was achieved without a problem under radiographic control.

\section{PATIENT 2}

A 52 year old woman who presented with abdominal pain and weight loss was shown to have coeliac disease on gastroscopic duodenal biopsy. Small intestinal radiology suggested the possibility of lymphoma as a complicating feature. At laparoscopy multiple segmental strictures compatible with lymphoma were seen; full thickness biopsy confirmed coeliac disease and was suggestive but not diagnostic of lymphoma. Subsequently she required a small bowel resection for subacute obstruction and histology of a $19 \mathrm{~cm}$ segment of small bowel confirmed $\mathrm{T}$ cell lymphoma associated with coeliac disease.

\section{PATIENT 3}

A 12 year old girl had suffered multiple injuries including a severe head injury in a road traffic accident two years previously. She remained severely brain damaged with limited volitional responses and required nasogastric enteral feeding. To facilitate continued enteral feeding while in residential care a laparoscopic feeding jejunostomy was performed. Tube displacement occurred at one month and, on this occasion, was replaced with a 12 Fr gauge Malecot catheter without difficulty under radiographic control. She remains on jejunal feeding at two months.

\section{Discussion}

This is the first report of the use of a laparoscopic method to obtain a full thickness intestinal biopsy. It avoids laparotomy but permits full visualisation of the abdominal viscera for diagnostic purposes and the selection of an appropriate site for biopsy. Our failure to obtain an unequivocal biopsy in patient 2 suggests that several biopsies should be obtained when the pathology is non-uniformly distributed. Although used by us for small bowel biopsy in adults, a similar technique would be applicable in children requiring full thickness colonic biopsy. A possible limiting factor could be the presence of intraabdominal adhesions but modern laparoscopic techniques, including laser dissection, permit adhesiolysis and the method should therefore be applicable to cases who have adhesions from previous surgery or past episodes of intraabdominal inflammation. None of these problems arose in our limited series.

When enteral feeding is required there are a number of options including fine bore nasogastic tubes, gastrostomy, and jejunostomy but whichever method is chosen there are hazards as well as advantages. Gastrostomy and jejunostomy tubes may be placed at laparotomy but since 1980 percutaneous endoscopic methods have been developed to provide enteral feeding into the stomach - percutaneous endoscopic gastrostomy or into the jejunum - percutaneous endoscopic jejunostomy. ${ }^{9-13}$ Feeding into the stomach (by nasogastric tube or gastrostomy) is often successful but there is a significant number of patients where this method increases the risk of gastrooesophageal reflux with aspiration and in such cases a jejunostomy may be performed.

Additionally in a small group of patients with obstructing gastric or duodenal disease, jejunostomy will be the sole feasible route. Although percutaneous endoscopic jejunostomy avoids a formal laparotomy, the procedure is somewhat complex and prone to complications producing morbidity and sometimes mortality.

Wolfsen et $a l^{14}$ reported tube failures in 53\% after percutaneous endoscopic jejunostomy and exchange or removal of the tube was necessary in $41 \%$ of the patients studied. Di Sario et al $l^{15}$ noted percutaneous endoscopic jejunostomy tube failures (occlusion, leakage, malposition, extrusion, kinking, and rupture) in $70 \%$ of patients which rendered the percutaneous endoscopic jejunostomy non-functional for $18 \%$ of the time. Fifteen per cent of patients had significant gastrointestinal haemorrhage from pressure necrosis from the tube or internal fixation device (crossbar). In both studies the serious complication of reflux and aspiration was recorded and tube migration back into the stomach, or oesophagus, was noted in $15 \%{ }^{14}$ to $35 \%{ }^{15}$ of patients and was probably the major cause of aspiration, although the aspiration of oropharyngeal secretions in patients with predisposing diseases was not excluded in some cases. Other factors too may play a role in reflux and aspiration after percutaneous endoscopic jejunostomy (and also percutaneous endoscopic gastrostomy) because anatomical displacement of the stomach is inherent in both techniques with fixation and a degree of distortion. There is conflicting evidence, however, on the effects of these changes on lower oesophageal sphincter pressure..$^{16-18}$ Di Sario concluded that because the tips of the 
catheters were of insufficient weight to keep the tubes in the jejunum unrecognised proximal migration of the tubes put patients at risk from reflux and aspiration and that refinements in methodology and catheter design are required before the additional use of this technique could be recommended.

Laparoscopic jejunostomy by the method described allows the bowel to be opened outside the abdomen for the insertion of a self retaining tube of ample calibre directly into the lumen without kinking or coiling; there is no possibility of displacement of the tip back into the stomach. Importantly, suture of the jejunum to the abdominal parietes ensures against leakage into the peritoneal cavity and facilitates easy replacement of the tube should this be necessary. These features coupled with the relative technical simplicity of the procedure suggests the jejunostomy by the laparoscopic route holds advantages over percutaneous endoscopic method. There has been one report of another technique for laparoscopic tube jejunostomy of which we were unaware when we treated out patients. In this publication the entire operation was performed intraperitoneally and required a specially designed needle holder for completion. ${ }^{19} \mathrm{We}$ feel that our technique is quicker and less complicated involving fewer puncture sites and avoiding the need for intraabdominal suturing with specialised instruments.

Neither full thickness intestinal biopsy nor tube jejunal feeding are commonly required but patients in whom they are indicated are usually ill and malnourished. Avoiding laparotomy by a minimally invasive laparascopic technique provides clear benefits including increased safety and a shorter period of recovery.
1 Schuffler MD, Rohrmann CA, Chaffee RG, Brand DL, Delaney JH, Young JH. Chronic intestinal pseudoobstruction. A report of 27 cases and review of the literature. Medicine 1981; 60: 173-96.

2 Mitros FA, Schuffler MD, Teja K, Anuras S. Pathological features of familial visceral myopathy. Hum Pathol 1982; 13: 825-33.

3 Risdon RA, Malone M. Paediatric gastrointestinal disease. In: Anthony PP, Macsween RNM, eds. Recent advances in histopathology. Edinburgh: Churchill Livingstone, 1989: histopatholo $223-49$.

4 Delany HM, Carnevale NJ, Garvey JW. Jejunostomy by a needle catheter technique. Surgery 1973; 73: 786-90

$5 \mathrm{McM}$ ahon MJ. The feeding jejunostomy. Br F Clin Pract Symp Suppl 1988; 63: 85-8.

6 Mansell PI, Tattershall RB, Balsitis M, Lowe J, Spiller RC. Megaduodenum due to hollow visceral myopathy successfully managed by duodenoplasty and feeding jejunostomy. Gut 1991; 32: 334-7.

7 McGonigal MD, Lucas CE, Ledgerwood AM. Feeding jejunostomy in patients who are critically ill. Surg Gynecol Obstet 1989; 168: 275-7.

8 Stellato TA, Gauderer MWL. Jejunostomy button as a new method for long term jejunostomy feedings. Surg Gynaecol Obstet 1989; 168: $552-4$.

9 Gauderer MWL, Ponsky JL, Izant RJ. Gastrostomy without laparotomy. A percutaneous endoscopic technique. F Pediatr laparotomy. A percur

10 Ponsky JL, Gauderer MWL. Percutaneous endoscopic gastrostomy: a non operative technique for feeding gastrostomy. Gastrointest Endosc 1981; 27: 9-11.

$11 \mathrm{Ho}$ CS. Percutaneous gastrostomy for jejunal feeding. Radiology 1983; 149: 595-6.

2 Ponsky JL, Aszodi A. Percutaneous endoscopic jejunostomy. Am $\mathcal{F}$ Gastroenterol 1984; 79: 113-6.

13 Gray RR, Ho CS, Yee A, Montanera W, Jones DP. Direct percutaneous jejunostomy. $A \mathcal{F}$ 1987; 149: 931-2.

14 Wolfsen HC, Kozarek RA, Ball TJ, Patterson DJ, Botoman VA. Tube dysfunction following percutaneous endoscopic gastrostomy and jejunostomy. Gastrointest Endosc 1990; 36: gastrostom $261-3$.

15 Di Sario JA, Foutch PG, Sanowski RA. Poor results with percutaneous endoscopic jejunostomy. Gastrointest Endosc percutaneous end $1990 ; 36: 257-60$.

16 Johnson DA, Hacker JF, Benjamin SB. Percutaneous endoscopic gastrostomy effects on gastro-oesophageal reflux and the lower oesophageal sphincter. Am J Gastroenterol 1987; 82: $622-4$.

17 Jolley SG, Tunell WP, Hoelzer DJ. Lower oesophageal pressure changes with tube gastrostomy; a causative factor of gastro-oesophageal reflux in children? F Pediatr Surg 1986; 21: 624-7.

18 Papaila JG, Vane DW, Colville C. The effect of various types of gastrostomy on the lower oesophageal sphincter. $F$ Pediatr Surg 1987; 22: 1198-202.

19 O'Regan PJ, Scarrow GO. Laparoscopic jejunostomy. Endoscopy 1990; 22: 39-40. 